\title{
Usage of a fibreoptic scope to verify tracheal tube placement in the pediatric population
}

\author{
David T. Wong, MD · Hui Yun V. Ip, FRCA
}

Received: 13 January 2009/Accepted: 12 February 2009/Published online: 3 April 2009

(C) Canadian Anesthesiologists' Society 2009

\section{To the Editor,}

I read with interest the excellent article by Harris et al. concerning misplacement of tracheal tubes within the pediatric population. ${ }^{1}$ Eighteen percent of the 257 chest radiographs from intubated children showed misplacement of tracheal tubes. Thirteen percent of the radiographs were too deep, while $5 \%$ were too shallow. Also, misplacement occurred in $37.7 \%$ of the children who were less than 1 -year-old. Since the reliability of mathematical formulae and clinical auscultation to estimate the proper depth of tracheal tube insertion has not been proven, Harris et al. ${ }^{1}$ advocate increased usage of fluoroscopy/radiography to confirm tracheal tube placement in pediatric surgical cases.

Although chest fluoroscopy/radiography has been an accepted and accurate means to assess tracheal tube placement in patients, there are several limitations: (1) The operating table must be suitable for fluoroscopy; (2) Imaging requires equipment and technicians to be readily available in the operating room; (3) Radiation exposure is present; and (4) If the tracheal tube migrates with intraoperative changes to the neck or body position, ${ }^{2,3}$ imaging equipment may not be available.

An alternative means to detect tracheal tube misplacement is available. The fibreoptic bronchoscope (FOB) has been used in both pediatric and adult populations to assess the distance from the carina to the tracheal tube tip and from the tracheal tube tip to the glottis. ${ }^{2-4}$ Compared to chest fluoroscopy/radiography, there are several potential advantages to using the FOB: (1) Assessing the tracheal tube location is instantaneous; (2) FOBs are readily

D. T. Wong, MD $(\bowtie) \cdot$ H. Y. V. Ip, FRCA

Toronto Western Hospital, University of Toronto,

Toronto, ON, Canada

e-mail: david.wong@uhn.on.ca available; (3) A FOB does not involve movement of the head and neck region; and (4) No radiation is involved.

On the other hand, there are limitations involved with using the FOB to assess tracheal tube placement: (1) The clinician must use a sufficiently small-sized pediatric bronchoscope to access tracheal tubes used for infants and newborns; and (2) An institution may not have sufficient FOBs to perform multiple examinations. The Foley Airway Stylet (FAST) is a portable fibreoptic device ${ }^{1}$ (Clarus Medical, Minneapolis, MN, USA) that consists of a battery source/handle, an eyepiece, and a detachable flexible fibreoptic stylet that can be sterilized and reused within $30 \mathrm{~min}$. The FAST stylet, however, will not pass through a tracheal tube of $\leq 5.0 \mathrm{~mm}$ internal diameter.

In summary, we congratulate Harris et al. for raising our awareness of the frequency of tracheal tube misplacement in the pediatric population. I believe fibreoptic scopes should be considered as an alternative to chest radiography for detecting and correcting tracheal tube misplacement in this population.

Conflicts of interest None declared.

\section{References}

1. Harris EA, Arheart KL, Penning DH. Endotracheal tube malposition within the pediatric population: a common event despite clinical evidence of correct placement. Can J Anesth. 2008; 55: 685-90.

2. Kim JH, Ro YJ, Min SW, Kim CS, Kim SD, Lee JH, et al. Elongation of the trachea during neck extension in children: implications of the safety of endotracheal tubes. Anesth Analg. 2005; 101: 974-7.

\footnotetext{
${ }^{1}$ American Nuclear Society. http://www.ans.org/pi/resources/dosechart/ (accessed February 2, 2009).
} 
3. Wong DT, Weng H, Lam E, Song HB, Liu J. Lengthening of the trachea during neck extension: which part of the trachea is stretched? Anesth Analg. 2008; 107: 989-93.

4. Wong DT, Kirkham K. Rapid estimation of distance from the tip of the tracheal tube to carina using fibreoptic bronchoscopy. Can J Anesth. 2008; 55: 787-8.

\section{Reply}

We appreciate Dr. Wong's comments and agree that fibreoptic bronchoscopy is an excellent tool to ascertain endotracheal tube position. As Dr. Wong notes, however, this approach does have limitations, perhaps most significantly, the need for a small-sized bronchoscope for the patient population most likely to have a misplaced endotracheal tube (ETT).

We agree that fluoroscopic confirmation of ETT placement is not suitable for all cases. However, many pediatric cases (e.g., orthopedic and spine surgeries) rely on the use of a portable fluoroscopic device (C-arm) in the operating room. Such cases where the equipment and personnel are present provide a perfect opportunity to examine ETT placement radiographically. The radiation exposure from a single posterior-anterior (PA) chest film (6 mrem) (see footnote 1) represents a small fraction of the total radiation the patient will receive. Due to the likelihood of tube migration with patient repositioning, we wait until the surgeons have positioned the patient to their satisfaction before checking the ETT placement. This approach seems prudent whether fluoroscopy or bronchoscopy is used to ascertain the tube's depth.

Conflicts of interest None declared.

Eric A. Harris, MD

Donald H. Penning, MD

Miller School of Medicine, University of Miami, Miami, FL, USA 